\title{
KLASIFIKASI CITRA DIGITAL BUMBU DAN REMPAH DENGAN ALGORITMA CONVOLUTIONAL NEURAL NETWORK (CNN)
}

\author{
Isna Wulandari ${ }^{1}$, Hasbi Yasin ${ }^{2}$, Tatik Widiharih ${ }^{3}$ \\ 1,2,3 Departemen Statistika, Fakultas Sains dan Matematika, Universitas Diponegoro \\ isnawulandari15@gmail.com
}

\begin{abstract}
The recognition of herbs and spices among young generation is still low. Based on research in SMK 9 Bandung, showed that there are $47 \%$ of students that did not recognize herbs and spices. The method that can be used to overcome this problem is automatic digital sorting of herbs and spices using Convolutional Neural Network $(\mathrm{CNN})$ algorithm. In this study, there are 300 images of herbs and spices that will be classified into 3 categories. It's ginseng, ginger and galangal. Data in each category is divided into two, training data and testing data with a ratio of $80 \%: 20 \%$. CNN model used in classification of digital images of herbs and spices is a model with 2 convolutional layers, where the first convolutional layer has 10 filters and the second convolutional layer has 20 filters. Each filter has a kernel matrix with a size of $3 \times 3$. The filter size at the pooling layer is $3 \times 3$ and the number of neurons in the hidden layer is 10 . The activation function at the convolutional layer and hidden layer is tanh, and the activation function at the output layer is softmax. In this model, the accuracy of training data is 0.9875 and the loss value is 0.0769 . The accuracy of testing data is 0.85 and the loss value is 0.4773 . Meanwhile, testing new data with 3 images for each category produces an accuracy of $88.89 \%$.
\end{abstract}

Keywords: image classification, herbs and spices, CNN.

\section{PENDAHULUAN}

Indonesia merupakan negara yang memiliki kekayaan alam terbesar kedua di dunia setelah Brazil. Salah satu kekayaan alam yang terkenal dari Indonesia adalah kekayaan bumbu dan rempahnya. Bumbu dan rempah memiliki manfaat utama sebagai penambah citarasa masakan. Selain itu, bumbu dan rempah juga bermanfaat dalam bidang kesehatan dan kecantikan. Rempah-rempah juga merupakan sumber daya hayati yang tidak dapat dipisahkan dari sejarah bangsa Indonesia. Kekayaan rempah-rempah di kepulauan Indonesia adalah awal mula petaka dan penyebab penjajahan bangsa asing di Indonesia Rempahrempah adalah daya tarik kepulauan Indonesia yang menarik bangsa-bangsa Eropa untuk menguasai dan memainkan peran politik dominan di wilayah Indonesia (Hakim, 2015).

Banyaknya manfaat bumbu dan rempah dengan segala daya tariknya dimasa lalu, ternyata tidak sejalan dengan pengenalan bumbu dan rempah dikalangan anak muda. Hasil penelitian di SMKN 9 Bandung mendapatkan hasil bahwa sebanyak 47\% siswa masih belum mengenali bumbu dan rempah pada saat pengolahan makanan Indonesia (Hikmatulloh et al, 2017).

Perkembangan ilmu pengetahuan dan teknologi pengolahan citra digital memungkinkan untuk memilah bumbu dan rempah secara otomatis. Klasifikasi citra merupakan alternatif untuk mengatasi masalah tersebut. Tujuan dari klasifikasi citra adalah menduplikasikan kemampuan manusia dalam memahami informasi citra digital, sehingga komputer dapat mengklasifikasikan objek berupa citra selayaknya manusia. Masalah yang dihadapi dalam klasifikasi citra adalah proses feature engineering yang terbatas pada dataset tertentu saja. Hal ini dikarenakan setiap citra memiliki perbedaan sudut pandang, perbedaan skala, perbedaan kondisi pencahayaan, deformasi objek, dan sebagainya.

Salah satu pendekatan yang berhasil untuk mengklasifikasikan citra adalah menggunakan Jaringan Syaraf Tiruan (Artificial Neural Network/ANN). Model ANN yang yang dapat digunakan untuk masalah klasifikasi objek berupa citra adalah Convolutional 
Neural Network (CNN). CNN merupakan operasi konvolusi yang menggabungkan beberapa lapisan pemrosesan, menggunakan beberapa elemen yang beroperasi secara paralel dan terinspirasi oleh sistem saraf biologis (Hu et al, 2015).

Pada penelitian ini metode CNN digunakan untuk mengklasifkasikan objek citra. Objek citra tersebut akan dibagi menjadi 3 kategori yaitu ginseng, jahe dan lengkuas. Tujuan dari penelitian ini adalah untuk mengatahui hyperparameter dan model CNN untuk pengenalan secara visual citra digital bumbu dan rempah serta untuk mengetahui tingkat akurasi dari hasil klasifikasi.

\section{TINJAUAN PUSTAKA}

\subsection{Citra Digital}

Citra digital merupakan suatu matriks dimana indeks baris dan kolomnya menyatakan suatu titik pada citra tersebut dan elemen matriksnya (yang disebut sebagai elemen gambar atau piksel) menyatakan tingkat keabuan pada titik tersebut (Fikriya et al, 2017). Pada penelitian ini digunakan citra berwarna. Citra berwarna tersusun atas tiga buah warna primer yaitu Red, Green dan Blue. Sebuah citra warna berukuran $B x C$ piksel dapat dituliskan menjadi tiga buah matriks yang masing-masing terdiri dari $B$ baris dan $C$ kolom, dimana setiap komponen pada matriks merepresentasikan nilai derajat keabuan pada masing-masing channel (Red, Green, Blue). Sebuah citra warna dapat direpresentasikan oleh matriks $\boldsymbol{I}_{p}$, dimana $\boldsymbol{I}_{1}$ merupakan matriks yang merepresentasikan derajat keabuan citra pada channel Red, $\boldsymbol{I}_{2}$ merupakan matriks yang merepresentasikan derajat keabuan citra pada channel Green dan $\boldsymbol{I}_{3}$ merupakan matriks yang merepresentasikan derajat keabuan citra pada channel Blue.

$$
\boldsymbol{I}_{p}=\left[\begin{array}{cccc}
\left(a_{11}\right)_{p} & \left(a_{12}\right)_{p} & \cdots & \left(a_{1 C}\right)_{p} \\
\left(a_{21}\right)_{p} & \left(a_{22}\right)_{p} & \cdots & \left(a_{2 C}\right)_{p} \\
\vdots & \vdots & \ddots & \vdots \\
\left(a_{B 1}\right)_{p} & \left(a_{B 2}\right)_{p} & \cdots & \left(a_{B C}\right)_{p}
\end{array}\right]
$$

Nilai untuk masing-masing komponen matriks $\boldsymbol{I}_{p}$ adalah sebagai

$$
\left(a_{i j}\right)_{p}=\frac{d_{p}}{255}
$$

$B$ adalah jumlah piksel baris pada citra dan $C$ adalah jumlah piksel kolom pada citra. $d_{p}$ merupakan nilai yang merepresentasikan derajat keabuan citra pada channel ke $p$, nilai $d_{p}$ diskrit dan memiliki range antara 0 hingga 255.

\subsection{Convolutional Neural Network}

Convolutional Neural Network merupakan salah satu jenis neural network yang biasanya digunakan untuk pengolahan data image (Santoso dan Ariyanto, 2018). CNN digunakan untuk melakukan klasifikasi data yang berlabel dengan menggunakan metode supervised learning. Pada supervised learning target yang diharapkan dari input yang diterima jaringan telah diketahui sebelumnya (Warsito, 2009).

Secara teknis, CNN adalah sebuah arsitektur yang dapat dilatih dan terdiri dari beberapa tahap. Input dari CNN berupa objek berupa citra. Proses mendeskripsikan citra menjadi feature yang dapat dipahami jaringan inilah yang membedakan $\mathrm{CNN}$ dengan jaringan syaraf lainnya. Arsitektur CNN terbagi menjadi 2 sebagai berikut

\section{a. Feature Learning}

Feature learning berfungsi untuk mengubah matriks input citra menjadi feature maps. Pada feature learning terdapat dua macam lapisan yaitu convolutional layer dan 
pooling layer. Jumlah convolutional layer dan pooling layer pada feature learning merupakan hyperparameter, artinya jumlahnya dapat berubah tergantung pada dataset yang digunakan. .

Convolutional layer melakukan operasi konvolusi, yaitu mengubah input menjadi feature maps dengan melakukan operasi dot antara matriks input dengan filter. Filter terdiri atas beberapa matriks bobot $\boldsymbol{K}$ atau biasa disebut dengan kernel. Banyaknya filter yang digunakan merupakan hyperparameter, jumlah filter ini akan menentukan jumlah feature maps yang dihasilkan. Banyaknya kernel pada layer ke $l$, sesuai dengan jumlah feature maps pada layer ke $l-1$. Banyaknya filter yang digunakan pada layer $l$ akan menentukan jumlah feature maps yang dihasilkan, dan jumlahnya sesuai dengan banyaknya kernel pada layer $l+1$.

Convolutional layer ini yang pertama kali menerima input berupa matriks dari citra digital. Setelah dilakukan operasi konvolusi, kemudian dilanjutkan menuju fungsi aktivasi. Pada penelitian ini fungsi aktivasi yang digunakan adalah tanh. Citra digital yang digunakan pada penelitian ini, memiliki panjang dan lebar yang sama. Sehingga matriks input dan feature maps yang dihasilkan merupakan matriks bujur sangkar. Secara matematis, operasi konvolusi untuk feature maps ke q dapat dituliskan sebagai berikut.

$$
\begin{aligned}
& \boldsymbol{S}_{q}(g, h)=\left(\sum_{p=1}^{P} \sum_{u=1}^{U} \sum_{v=1}^{U} \boldsymbol{I}_{p}(g+u, h+v) \cdot \boldsymbol{K}_{p q}(u, v)\right)+b_{q} \\
\text { dengan }: & g=0,1,2, \ldots, G-1 \\
h & =0,1,2, \ldots, G-1 \\
q & =1,2, \ldots, Q
\end{aligned}
$$

$G$ merupakan banyaknya kolom/baris pada feature maps. $U$ adalah banyaknya baris/kolom pada kernel. $Q$ merupakan jumlah feature maps, jumlahnya sama dengan banyaknya filter. $P$ adalah jumlah matriks kernel, jumlahnya sama dengan banyaknya channel matriks input.

$\boldsymbol{S}_{q}(g, h)$ merupakan elemen feature map ke- $q$, pada baris ke- $g$ kolom ke- $h$. $\boldsymbol{I}_{p}(g+u, h+v)$ adalah elemen matriks input channel ke- $q$, pada baris ke ke- $g+u$ kolom ke- $h+v$. $\boldsymbol{K}_{p q}(u, v)$ adalah elemen matriks kernel $p q$, pada baris ke- $u$ kolom ke- $v \cdot b_{q}$ merupakan bias pada filter ke- $q$.

Pooling layer pada model $\mathrm{CNN}$ biasanya disisipkan secara teratur setelah convolutional layer. Pada dasarnya pooling layer terdiri dari sebuah filter dengan ukuran dan jumlah pergeseran tertentu, yang akan secara bergantian bergeser pada seluruh area feature map. Apabila filter pada pooling layer tidak dapat menjangkau seluruh bagian pada feature map, maka bagian yang tidak terjangkau akan dihilangkan tanpa melalui proses pooling. Terdapat dua macam pooling yang biasa digunakan yaitu average pooling dan max-pooling. Nilai yang diambil pada average pooling adalah nilai rata-rata, sedangkan pada max-pooling adalah nilai maksimal. Pada penelitian ini digunakan max-pooling.

b. Fully Connected Layer

Feature map yang dihasilkan dari feature learning masih berbentuk matriks, sehingga harus dilakukan flatten atau reshape feature map mejadi sebuah vektor kolom $\boldsymbol{x}$ agar bisa digunakan sebagai input dari fully connected layer. Setiap komponen pada vektor $\boldsymbol{x}$ menjadi neuron input pada fully connected layer.

Perbedaan antara fully connected layer dengan convolutional layer adalah neuron di convolutional layer terhubung hanya ke daerah tertentu pada input, sementara pada fully connected layer memiliki neuron yang secara keseluruhan terhubung. Operasi pada fully connected layer dapat dituliskan sebagai berikut 


$$
\begin{aligned}
\text { dengan }: r & =1,2,3, \ldots, R \\
R & =\text { jumlah neuron output } \\
J \quad & =\text { jumlah neuron input } \\
z_{r} & =\text { output pada neuron ke- } r \\
x_{c} & =\text { input pada neuron } \mathrm{ke}-c \\
W_{t r} & =\text { bobot antara neuron input ke-c menuju neuron ouput ke- } r \\
b_{r} & =\text { bias untuk neuron output } \mathrm{ke}-r
\end{aligned}
$$

\subsection{Dropout}

Dropout merupakan proses mencegah terjadinya overfitting dan juga mempercepat proses learning. Dropout mengacu kepada menghilangkan neuron yang berupa hidden mapun layer yang visible di dalam jaringan. Neuron yang akan dihilangkan akan dipilih secara acak (Abhirawa et al, 2017). Hal ini, artinya bahwa kontribusi neuron yang dibuang akan dihentikan sementara jaringan dan bobot baru juga tidak diterapkan pada neuron pada saat melakukan backpropagation.

\subsection{Softmax}

Softmax classifier merupakan bentuk lain dari algoritma Logistic Regression yang dapat digunakan untuk mengklasifikasi lebih dari dua kelas. Standar klasifikasi yang biasa dilakukan oleh algoritma Logistic Regression adalah tugas untuk klasifikasi kelas biner (Ilahiyah dan Nilogiri, 2018). Berikut adalah fungsi yang diberikan :

$$
f\left(z_{r}\right)=\frac{e^{z_{r}}}{\sum_{m=1}^{M} e^{z_{m}}}
$$

$z_{r}$ merupakan nilai pada neuron ke- $r$ sesuai dengan persamaan (3). Nilai $M$ merupakan jumlah kategori yang diklasifikasikan. Output yang dihasilkan pada persamaan (4) bernilai antara nol sampai dengan satu. Nilai $f\left(z_{r}\right)$ merupakan probabilitas untuk setiap kategori. Semua nilai $f\left(z_{r}\right)$ apabila dijumlahkan akan bernilai satu.

\subsection{Crossentropy Loss}

Loss Function adalah fungsi yang menggambarkan kerugian yang terkait dengan semua kemungkinan yang dihasilkan oleh model. Loss Function yang baik adalah fungsi yang menghasilkan error yang diharapkan paling rendah. Persamaan loss function dengan crossentropy sebagai berikut.

$$
L=-\frac{1}{N} \sum_{n=1}^{N} \sum_{r=1}^{M} y_{r, n} \log \left(f\left(z_{r}\right)_{n}\right)
$$

Nilai $\mathrm{N}$ menunjukkan jumlah data citra dan nilai M menunjukkan jumlah kategori. $f\left(z_{r}\right)$ merupakan fungsi softmax classifier pada persamaan (4). $y_{r, n}$ merupakan indikator binner, nilainya 1 untuk kelas yang sesuai dan 0 untuk kelas yang tidak sesuai. apabila Gambaran umum crossentropy loss function adalah meminimalkan kemungkinan log negatif dari dataset, yang merupakan ukuran langsung dari performa prediksi model. Kinerja suatu model semakin baik apabila nilai $L$ semakin mendekati nol.

\subsection{Confusion Matrix}

Salah satu metode untuk mengukur performa dari suatu model klasifikasi adalah dengan nilai akurasi dari suatu model. Beberapa istilah yang merupakan dasar dalam pencarian nilai akurasi adalah true positive (TP), true negative (TN), false positive (FP), dan false negative 
(FN). Istilah-istilah tersebut biasa dirangkum sebagai suatu matriks yang disebut confusion matrix sebagaimana ditunjukkan pada berikut.

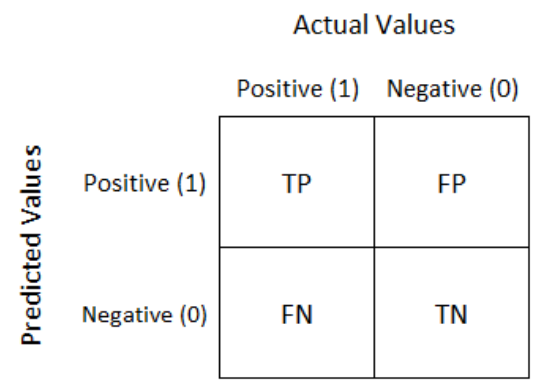

Gambar 1. Confusion Matrix

Nilai akurasi dalam klasifikasi adalah presentase ketepatan record data yang diklasifikasikan dengan tepat setelah dilakukan pengujian pada hasil klasfikasi. Perhitungan akurasi dengan confusion matrix adalah sebagai berikut.

$$
\text { akurasi }=\frac{T P+T N}{T P+F P+F N+T N}
$$

\section{METODE PENELITIAN}

Data yang digunakan dalam penelitian ini adalah citra digital bumbu dan rempah yang diambil dengan cara crawling pada search engine google. Citra digital yang digunakan terdiri dari tiga kategori yaitu ginseng, jahe dan lengkuas. Total citra yang dikumpulkan untuk sampel sebanyak 300, dengan masing-masing kategori sebanyak 100 citra. Data tersebut dibagi menjadi 2 yaitu data training dan data testing, dengan perbandingan data training dan data testing $80 \%: 20 \%$.

Software yang digunakan pada penelitian ini adalah fatkun batch download image dan RStudio. Fatkun batch download image digunakan untuk crawling data pada search engine google dan RStudio digunakan untuk mengklasifikasikan citra digital. Package pada RStudio yang digunakan adalah Keras dan EBImage.

Tahapan analisis pada penelitian ini adalah sebagai berikut

1. Input data dan beri label pada masing-masing citra digital sesuai dengan kategorinya.

2. Melakukan preprocessing pada data citra.

3. Menentukan hyperparameter untuk model CNN, meliputi jumlah convolutional layer, jumlah filter pada convolutional layer, ukuran matriks kernel dan filter pooling, jumlah neuron pada hidden layer dan fungsi aktivasi.

4. Menentukan bobot awal dan iterasi $i_{\text {max }}$.

5. Inisialisasi bobot.

6. Melakukan training dan testing.

7. Menghitung tingkat akurasi sesuai dengan persamaan (6).

8. Menghitung loss function sesuai dengan persamaan (5).

9. Apabila iterasi $\geq$ iterasi $_{\max }$ maka lanjut ke proses selanjutnya, apabila tidak maka kembali pada proses 5 .

10. Mendapatkan bobot akhir dan model klasifikasi sesuai dengan persamaan (4).

11. Memilih model terbaik berdasarkan tingkat akurasi terbesar pada data testing.

12. Melakukan evaluasi hasil klasifikasi.

\section{HASIL DAN PEMBAHASAN}


Citra yang diunduh dengan fatkun batch download image dibagi menjadi 3 kategori yaitu ginseng, jahe dan lengkuas. Jumlah data citra pada masing-masing kategori adalah 100. Citra yang telah diunduh, kemudian diberi nama sesuai dengan kategori yang telah ditentukan. Ginseng diberi nama 'ginseng_(nomor).jpg', jahe diberi nama dengan 'jahe_(nomor).jpg' dan lengkuas diberi nama 'lengkuas_(nomor).jpg'. Berikut merupakan contoh citra yang digunakan pada klasifikasi citra digital bumbu dan rempah dengan metode CNN.

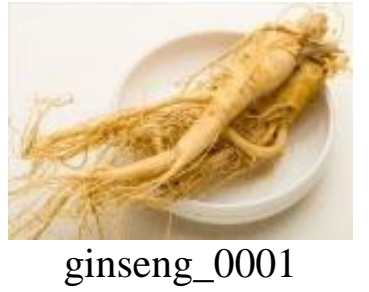

ginseng_0001

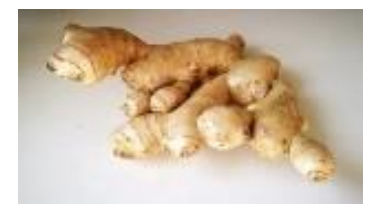

jahe_0001

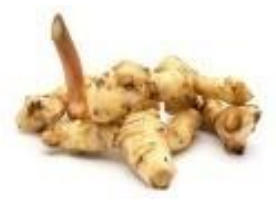

lengkuas_0001

Gambar 2. Contoh Citra Digital Untuk Klasifikasi

\subsection{Preprocessing Citra}

Tahap preprocessing citra dilakukan sebagai berikut.

a. Resize

Resize citra adalah proses merubah ukuran piksel suatu citra digital. Citra yang diunduh dari search engine google memiliki ukuran yang beragam. Pada penelitian ini digunakan citra dengan ukuran 46x46. Citra yang sudah diubah ukurannya tersebut kemudian akan direpresentasikan secara numerik dalam bentuk matriks. Sehingga sebuah citra digital akan diubah menjadi 3 buah matriks (sesuai dengan channel red, green, blue), masing-masing berukuran 46x46.

b. Membuat data training dan testing

Pembagian data training dan testing pada penelitian ini menggunakan perbandingan $80 \%$ : 20\%. Jumlah citra pada masing-masing kategori adalah 100. Pembagian data dilakukan urut dari awal. Pada masing-masing kategori, citra urutan ke 1 hingga 80 akan menjadi data training dan citra dengan urutan ke 81 hingga 100 akan menjadi data testing.

c. Combine

Combine berfungsi untuk menggabungkan data citra. Proses penggabungan citra ini dilakukan masing masing untuk data training dan data testing. Sebelum proses combine, setiap citra direpresentasikan sebagai matriks multidimensi dengan ukuran 46x46x3. Setelah proses combine, masing-masing matriks citra akan digabungkan menjadi matriks multidimensi, sehingga untuk citra training akan memiliki dimensi 46x46x3x240 dan citra testing memiliki dimensi 46x46x3x60. Nilai 240 dan 60 sesuai dengan jumlah citra training dan testing.

d. Reorder Dimension

Proses reorder dimension berfungsi untuk mengatur penempatan dimensi matriks citra. Dimensi citra training hasil proses combine adalah 46x46×3x240 dan dimensi citra testing hasil proses combine adalah $46 \times 46 \times 3 \times 60$. Urutan penempatan dimensi pada combine adalah (jumlah baris pada matriks citra) $\mathrm{x}$ (jumlah kolom pada matriks citra) $\mathrm{x}$ (jumlah channel citra) x (jumlah data).

Pada reorder dimension, urutan dimensi pada matriks citra akan diubah menjadi (jumlah data) $\mathrm{x}$ (jumlah jumlah baris pada matriks citra) $\mathrm{x}$ (jumlah kolom pada matriks citra) x (jumlah channel citra). Sehingga output dari reorder dimension adalah matriks 
multidimensi dengan dimensi 240x46x46x3 untuk citra training dan dimensi $60 \times 46 \times 46 \times 3$ untuk citra testing.

e. Labelling

CNN merupakan salah satu jenis algoritma supervised learning. Sehingga diperlukan labelling data pada tahapan preprocessing. Labelling berfungsi untuk memberikan nilai target untuk masing-masing citra. Target dari citra ginseng adalah kategori 0 , target dari citra jahe adalah kategori 1 dan target dari citra lengkuas adalah kategori 2. Labelling dilakukan baik untuk data training maupun testing.

\subsection{Arsitektur CNN}

Jumlah convolutional layer, jumlah filter, ukuran kernel, jumlah neuron pada hidden layer dan fungi aktivasi yang digunakan pada CNN merupakan hyperparameter. Arsitektur jaringan pada klasifikasi cita digital bumbu dan rempah dapat dijelaskan sebagai berikut.

a. Convolutional Layer 1

Pada layer ini matriks input berjumlah 3 sesuai dengan jumlah channel (red,green, blue) dimana masing-masing matriks berukuran 46x46. Filter yang digunakan sebanyak 10. Masing-masing filter terdiri atas 3 matriks kernel, jumlah matriks kernel dalam setiap filter jumlahnya sesuai dengan banyaknya matriks input. Ukuran setiap matriks kernel adalah 3x3. Pada layer ini digunakan fungsi akitivasi tanh.

b. Pooling Layer 1

Output dari convolutional layer 1 yaitu 10 matriks, masing-masing berukuran $44 \times 44$. Matriks ini kemudian menjadi input pada pooling layer 1 . Pada layer ini, ukuran filter yang digunakan adalah $3 \times 3$. Pada pooling layer 1 , filter tidak dapat menjangkau seluruh bagian dari feature maps, karena filter berukuran $3 \times 3$ sementara feature maps berukuran $44 x 44$. Filter dapat menjangkau seluruh bagian feature maps apabila ukuran feature maps merupakan kelipatan dari ukuran filter. Sehingga pada pooling layer 1, feature maps yang akan digunakan untuk operasi pooling hanya baris dan kolom ke-1 sampai dengan baris dan kolom ke-42. Sementara itu, baris dan kolom ke-43 dan ke-44 akan dihilangkan tanpa melalui operasi pooling.

c. Convolutional Layer 2

Pada layer ini matriks input berjumlah 10 dengan masing-masing matriks berukuran $14 x 14$. Filter yang digunakan sebanyak 20. Masing-masing filter terdiri atas 10 matriks kernel, banyaknya matriks kernel dalam setiap filter sesuai dengan banyaknya matriks input. Ukuran setiap matriks kernel adalah 3x3. Pada layer ini digunakan fungsi akitivasi tanh.

d. Pooling Layer 2

Output dari convolutional layer 2 yaitu 20 matriks, masing-masing berukuran 12x12. Matriks ini kemudian menjadi input pada pooling layer. Pada layer ini ukuran filter yang digunakan adalah $3 \times 3$. Sehingga output yang dihasilkan dari pooling layer 2 adalah 20 matriks dengan ukuran $4 \times 4$. Nilai 20 sesuai dengan jumlah matriks input pada layer ini.

e. Flatten Layer

Pada flatten layer, input berupa matriks dari pooling layer akan dirubah menjadi satu vektor kolom. Pada layer ini terdapat 20 matriks input, masing masing berukuran. Sehingga output shape dari flatten layer adalah vektor kolom dengan banyak baris 320 .

f. Hidden Layer

Setiap komponen dari vektor kolom hasil flatten akan diubah menjadi neuron input pada hidden layer. Sehingga input pada layer ini berjumlah 320. Jumlah neuron di layer ini ada 10. Pada layer ini semua bagian saling terhubung dan memiliki bobot. Selain itu, 
terdapat bias yang terhubung ke masing-masing neuron pada hidden layer. Sehingga terdapat 10 nilai output yang dihasilkan, sesuai dengan banyaknya neuron output.

g. Output Layer

Output layer pada CNN merupakan bagian dari fully connected layer. Sehingga antar neuron saling terhubung. Input pada layer ini adalah 10, dan jumlah neuron di layer ini ada 3. Selain itu terdapat sebuah bias yang terhubung pada seluruh neuron output. Sehingga terdapat 3 nilai output yang dihasilkan, sesuai dengan jumlah kategori citra.

\subsection{Hasil Klasifikasi.}

a. Data Training

Hasil klasifikasi yang didapatkan dari data training ditunjukkan melalui confusion matrix seperti berikut ini.

Tabel 1. Confussion Matrix Data Training

\begin{tabular}{llll}
\hline \multirow{2}{*}{ Prediksi } & Aktual & & \\
\cline { 2 - 4 } & Ginseng & Jahe & Lengkuas \\
\hline Ginseng & 79 & 0 & 0 \\
\hline Jahe & 1 & 78 & 0 \\
\hline Lengkuas & 0 & 2 & 80 \\
\hline
\end{tabular}

Berdasarkan hasil klasifikasi pada Tabel 1 dapat dilihat bahwa pada citra ginseng terdapat 1 citra yang salah prediksi dan masuk ke kategori jahe. Pada citra jahe, terdapat 78 citra yang diklasifikasikan dengan benar, dan terdapat 2 citra yang salah salah prediksi sehingga masuk ke kategori lengkuas. Pada citra lengkuas, seluruh data training diklasifikan dengan tepat. Nilai akurasi klasifikasi dari data training adalah 0,9875 atau 98,75\%. Nilai akurasi 98,75\% artinya sebanyak 98,75\% dari data training dapat diklasifikasikan secara tepat dengan metode CNN. Sementara itu, nilai loss data training adalah 0,0769 .

b. Data Testing

Hasil klasifikasi data testing dapat ditunjukkan melalui confussion matrix sebagai berikut.

Tabel 2. Confussion Matrix Data Testing

\begin{tabular}{llll}
\hline \multirow{2}{*}{ Prediksi } & Aktual & & \\
\cline { 2 - 4 } & Ginseng & Jahe & Lengkuas \\
\hline Ginseng & 17 & 0 & 0 \\
\hline Jahe & 0 & 17 & 3 \\
\hline Lengkuas & 3 & 3 & 17 \\
\hline
\end{tabular}

Berdasarkan hasil klasifikasi data testing pada Tabel 2 dapat dilihat bahwa pada citra ginseng dari 20 citra terdapat 3 citra yang salah prediksi dan masuk ke kategori lengkuas. Pada citra jahe, terdapat 17 citra yang diklasifikasikan dengan benar, dan terdapat 3 citra yang salah salah prediksi sehingga masuk ke kategori lengkuas. Pada citra lengkuas, terdapat 17 citra yang diklasifikasikan dengan tepat, sisanya 3 citra salah diklasifikasikan masuk ke ketegori jahe. Akurasi hasil klasifikasi dari data training adalah 0,85 atau $85 \%$. Akurasi $85 \%$ artinya metode Convolutional Neural Network dapat mengenali data bumbu dan rempah secara visual dengan tepat sebesar $85 \%$. Sementara itu, nilai loss data testing adalah 0,4773.

c. Data Baru

Setelah didapatkan model, dilakukan pengujian hasil klasifikasi pada data citra baru. Terdapat 9 buah citra yang masing-masing 3 citra untuk setiap kategori. Pada seluruh citra baru, perlu dilakukan tahapan preprocessing seperti pada data training dan 
data testing. Setelah dilakukan tahapan preprocessing, dilakukan klasifikasi citra dengan model yang telah dibentuk pada proses training dan testing.

Pada klasifikasi dengan CNN, probabilitas setiap kategori akan dihitung untuk menentukan hasil klasifikasi dari masing-masing citra. Nilai probabilitas terbesar menyatakan kategori dari citra tersebut.

Tabel 3. Confussion Matrix Data Baru

\begin{tabular}{llll}
\hline \multirow{2}{*}{ Prediksi } & Aktual & & \\
\cline { 2 - 4 } & Ginseng & Jahe & Lengkuas \\
\hline Ginseng & 3 & 0 & 1 \\
\hline Jahe & 0 & 3 & 0 \\
\hline Lengkuas & 0 & 0 & 2 \\
\hline
\end{tabular}

Berdasarkan Tabel 3, dilihat bahwa pada klasifikasi citra baru, seluruh citra ginseng dan jahe dapat diklasifikasikan dengan tepat. Sementara itu pada citra lengkuas, terdapat dua citra yang dapat diklasifikasikan dengan tepat, dan terdapat sebuah citra yang salah masuk ke kategori ginseng Nilai akurasi klasifikasi dari data baru adalah 0,8889 atau $88,89 \%$. Akurasi $88,89 \%$ artinya metode Convolutional Neural Network dapat mengenali data bumbu dan rempah secara visual dengan tepat sebesar $88,89 \%$.

\section{KESIMPULAN}

Model CNN yang digunakan pada klasifikasi citra digital bumbu dan rempah adalah model dengan 2 convolutional layer, dimana convolutional layer pertama memiliki jumlah filter 10 dan convolutional layer kedua memiliki jumlah filter 20. Pada masing-masing filter terdapat matriks kernel denga ukuran $3 \times 3$. Ukuran filter pada pooling layer adalah $3 \times 3$ dan jumlah neuron pada hidden layer adalah 10. Fungsi aktivasi pada convolutional layer dan hidden layer adalah tanh, dan fungsi aktivasi pada output layer adalah softmax. Pada model ini didapatkan nilai akurasi data training sebesar 0,9875 dan nilai loss 0,0769. Nilai akurasi data testing sebesar 0,85 dan nilai loss 0,4773. Sementara itu, pengujian dengan data baru yaitu masing-masing 3 citra untuk setiap kategori menghasilkan akurasi sebesar 88,89\%.

\section{DAFTAR PUSTAKA}

Abhirawa, H., Jondri, \& Arifianto, A. 2017. Pengenalan Wajah Menggunakan Convolutional Neural Network. e-Proceding of Engineering Vol. 4, No. 3 : Hal. 49074916.

Fikriya, Z. A., Irawan, M.I., \& Soetrisno. 2017. Implementasi Extreme Learning Machine untuk Pengenalan Object Citra Digital. Jurnal Sains dan Seni ITS Vol. 6, No. 1 : Hal. A18-A23.

Hakim, L. 2015. Rempah dan Herba Kebun Pekarangan Rumah Masyarakat Keragaman Sumber Fitokarma dan Wisata Kesehatan-Kebugaran. Yogyakarta : Diandra Pustaka Indonesia.

Hikmatulloh, E., Lasmanawati, E., \& Setiawati, T. 2017. Manfaat Pengetahuan Bumbu dan Rempah Pada Pengolahan Makanan Indonesia Siswa SMKN 9 Bandung. Media Pendidikan, Gizi dan Kuliner Vol. 6, No. 1 : Hal. 42-50.

Hu, F., Xia, G. S., Hu, J., \& Zhang, L. 2015. Transferring Deep Convolutional Neural Network for Scene Classification of High-Resolution Image Sensing Imagery. Remote Sens : Hal. 14680-14707. 
Ilahiyah, S., \& Nilogiri, A. 2018. Implementasi Deep Learning Pada Identifikasi Jenis Tumbuhan Berdasarkan Citra Daun Menggunakan Convolutional Neural Network. Jurnal Sistem \& Teknologi Informasi Indonesia Vol. 3, No 2 : Hal. 49-56.

Santoso, A., \& Ariyanto, G. 2018. Implementasi Deep Learning Berbasis Keras untuk Pengenalan Wajah. Jurnal Emitor Vol. 18, No. 01 : Hal. 15-21.

Warsito, B. 2009. Kapita Selekta Statistika Neural Network. Semarang : BP Undip Semarang. 